\title{
Enhanced expression of KIF4A in colorectal cancer is associated with lymph node metastasis
}

\author{
YOSHIKO MATSUMOTO, MOTONOBU SAITO, KATSUHARU SAITO, YASUYUKI KANKE, \\ YOHEI WATANABE, HISASHI ONOZAWA, SUGURU HAYASE, WATARU SAKAMOTO, TERUHIDE ISHIGAME, \\ TOMOYUKI MOMMA, KENSUKE KUMAMOTO, SHINJI OHKI and SEIICHI TAKENOSHITA
}

\author{
Department of Organ Regulatory Surgery, School of Medicine, Fukushima Medical University, \\ Fukushima 960-1295, Japan
}

Received May 24, 2016; Accepted January 19, 2017

DOI: $10.3892 / \mathrm{ol} .2017 .7555$

\begin{abstract}
Kinesin family member 4A (KIF4A) is a member of the kinesin 4 subfamily of kinesin-related proteins and serves an important role in cell division. The expression levels of KIF4A have been investigated in numerous types of cancer, including cervical, lung, oral, and breast cancer, and are established to be associated with poor patient prognosis. However, the role of KIF4A, as well as its expression in colorectal cancer (CRC), remains to be elucidated. Therefore, the current study investigated KIF4A expression levels in patients with $\mathrm{CRC}$ and demonstrated that its levels were increased in tumor tissues compared with non-tumor tissues. To investigate the functional role of KIF4A, KIF4A was knocked down in CRC cells and cell viability was evaluated. CRC cells with KIF4A knockdown exhibited lower cell proliferation compared with control cells. In addition, KIF4A expression levels, as determined by immunohistochemistry, were compared with the expression of $\mathrm{Ki}-67$, but no significant associations were observed in the patients with CRC. Therefore, KIF4A was found to be upregulated in patients with CRC and downregulation of KIF4A reduced cell proliferation in CRC cells. These results suggest that KIF4A may be a potential therapeutic target, which may improve the outcomes of patients with CRC.
\end{abstract}

\section{Introduction}

Colorectal cancer (CRC) is the third most frequently diagnosed cancer in males and females in the United States (1). As surgery alone is not sufficient to cure the majority of patients with CRC, adjuvant chemotherapy or radiation therapy is also typically administered to patients (2). A combination of chemotherapy

Correspondence to: Dr Seiichi Takenoshita, Department of Organ Regulatory Surgery, School of Medicine, Fukushima Medical University, 1 Hikarigaoka, Fukushima 960-1295, Japan

E-mail: takenoss@fmu.ac.jp

Key words: colorectal cancer, kinesin family member 4A, cell proliferation, lymph node metastasis, Ki-67 with folinic acid, 5-fluorouracil and oxaliplatin and folinic acid, 5-fluorouracil and irinotecan has become the standard treatment regimen for patients with CRC, providing a higher response rate compared with conventional chemotherapy (3-6). However, the response rates of current chemotherapy regimes are $<50 \%$ and therefore, alternative molecular targets are required to improve drug response rates (3-6).

The kinesin superfamily proteins (KIFs) are microtubule-dependent molecular motors that convert the chemical energy from ATP hydrolysis to the mechanical action of transporting cargo along microtubules, suggesting that they have an important role in intracellular transport and cell division (7). KIFs are classified into 14 distinct families with varying structural and functional characteristics $(8,9)$. Among these, KIF4A is considered to have a role in chromosome condensation and is involved in the segregation machinery that functions in mitotic division $(10,11)$. Alterations in the regulation of KIF4A promote abnormal spindle separation and lead to aneuploidy in daughter cells (10). Cells with aneuploidy are characterized by loss or gain of genetic material (11). Therefore, KIF4A expression levels may be associated with cancer progression.

It has been reported that KIF4A expression is altered in numerous types of cancer, including cervical (12), lung (13), gastric (14), oral (15) and breast cancer (16). These alterations in cancer cells suggest that the biological function of KIF4A is associated with the regulation of the cell cycle and cellular proliferation. A previous microarray study found that there was increased expression of KIF4A mRNA in human cervical cancer (12). KIF4A expression was identified as being upregulated in lung cancer and was significantly associated with the male gender, non-adenocarcinoma histology and a reduced survival rate in patients with non-small cell lung cancer (13). In an immunohistochemical (IHC) evaluation of 106 patients with oral squamous cell cancer, KIF4A expression levels in cancer tissue were significantly increased compared with those in normal tissue (15). A previous study demonstrated that estrogen induces a number of KIFs, including KIF4A, and increased levels of KIF4A are associated with reduced relapse-free survival of patients with breast cancer that are positive for the estrogen receptor (16). These previous studies indicated that KIF4A may function as an oncogene in a numerous types of cancer, but the expression and role of KIF4A in CRC remain to be elucidated. The present study 
investigated the biological significance of KIF4A expression levels to clarify the function of KIF4A in CRC.

\section{Materials and methods}

Clinical tissue samples from patients. A total of 258 surgical specimens were obtained for analysis from 258 patients with CRC that underwent surgical resection at Fukushima Medical University Hospital (Fukushima, Japan) between January 1991 and December 2011. In 63/258 of the tissues, mRNA was extracted from cancer tissue and adjacent non-tumor tissue. Information regarding age, gender, tumor-mode-metastasis (TNM) stage (the 7th classification) $(17,18)$ and pathological diagnosis, including lymphatic and venous invasion, were retrospectively collected. At the time of primary tumor resection, carcinoma tissues were staged according to the Union for International Cancer Control classification $(17,18)$. Written informed consent was obtained from all patients. This study was approved by the Ethics Committee of Fukushima Medical University (ref. no. 2117).

Cell line culture. The RKO, SW480, Lovo, HCT15, SW48, LS174T, SW620, LS180 and HCT116 colon cancer cell lines were used in this study and all were obtained from the American Type Culture Collection (Manassas, VA, USA). The cells were cultured in the recommended media (Dulbecco's modified Eagle's medium; Thermo Fisher Scientific, Inc., Waltham, MA, USA) for RKO, LS174T and LS180 and Roswell Park Memorial Institute-1640 medium (Sigma-Aldrich; Thermo Fisher Scientific, Inc.) for SW480, Lovo, HCT15, SW48, SW620 and HCT116 supplemented with $10 \%$ fetal bovine serum (Thermo Fisher Scientific, Inc.). Cells were maintained in a $37^{\circ} \mathrm{C}$ incubator in an atmosphere containing $5 \% \mathrm{CO}_{2}$. Cells were regularly monitored using a light microscope and subcultured once they reached $80-90 \%$ confluency.

Reverse transcription-quantitative polymerase chain reaction (RT-qPCR). Total RNA was extracted from RKO, SW480, Lovo, HCT15, SW48, LS174T, SW620, LS180 and HCT116 cells using TRIzol ${ }^{\circledR}$ reagent (Thermo Fisher Scientific, Inc.) according to the manufacturer's protocol as previously described (19). Complementary DNA (cDNA) was synthesized from $5 \mu \mathrm{g}$ of total RNA with a random hexamer using the SuperScript ${ }^{\circledR}$ III First-Strand Synthesis system (Thermo Fisher Scientific, Inc.). These cDNAs were used for the measurement of gene expression with an Applied Biosystems ${ }^{\circledR} 7500$ Real-time PCR system (Thermo Fisher Scientific, Inc.) using TaqMan ${ }^{\circledR}$ probes of KIF4A and $\beta$-actin which were used as internal controls (KIF4A, \#Hs01020169_m1; $\beta$-actin, \#Hs99999903_m1; Thermo Fisher Scientific, Inc.) and experiments were performed in triplicate with blinded patient information. The thermocycling conditions were as follows: $50^{\circ} \mathrm{C}$ for $2 \mathrm{~min}$ for AMPerase activation, $95^{\circ} \mathrm{C}$ for $10 \mathrm{~min}$ for Taq activation, $95^{\circ} \mathrm{C}$ for $15 \mathrm{sec}$ for denaturation and $60^{\circ} \mathrm{C}$ for $1 \mathrm{~min}$ for annealing and extension. Relative KIF4A gene expression was calculated using the $2^{-\Delta \Delta C q}$ method (20).

IHC staining and evaluation. IHC staining was performed on paraffin-embedded histological sections (4- $\mu \mathrm{m}$ thick) using a polymer peroxidase method, in which colon cancer specimens were fixed in $20 \%$ phosphate-buffered formalin $(\mathrm{pH}$ 7.4) at room temperature overnight. Briefly, following deparaffinization with xylene and rehydration using alcohol-water mixtures, prior to heat treatment in $10 \mathrm{mM}$ citric acid $(\mathrm{pH}$ 6.0) for antigen retrieval, the sections were treated with $0.3 \%$ hydrogen peroxide in methanol for $30 \mathrm{~min}$ to block endogenous peroxidase activity. Following washing with PBS, the sections were incubated with rabbit polyclonal anti-KIF4A antibody (dilution, 1:300; \#ab122227; Abcam, Cambridge, UK) and mouse monoclonal anti-MIB-1 (Ki-67) antibody (dilution, 1:100; Dako; Agilent Technologies $\mathrm{GmbH}$, Waldbronn, Germany) at $4^{\circ} \mathrm{C}$ overnight. Following washing with PBS the slides were treated with a peroxidase-labeled polymer conjugated to goat anti-rabbit immunoglobulin (Dako EnVision+ System-HRP Labelled Polymer; ready-to-use; \#K4003; Dako; Agilent Technologies) according to the manufacturer's protocol, as the secondary antibody for $30 \mathrm{~min}$ at room temperature. The staining was visualized with diaminobenzidine, followed by counterstaining with hematoxylin. Colon cancer cell lines were also immunostained for KIF4A and evaluated for staining intensity.

Expression of these proteins was evaluated using optical microscopy (BX43; Olympus Corporation, Tokyo, Japan) as positive when the nucleus of the cancerous tissue and the total field of view were observed at x400 magnification. Blinded to the patients' characteristics and clinical outcomes, the staining of each specimen was evaluated. The number of stained cells was counted in per 1,000 cancer cells in the field of cancer tissue by two investigators. The rate of positively stained cells was classified as follows: $0,0-5 ; 1,6-20 ; 2,21-50 ; 3,51-100 \%$. The staining intensity was scored as 0 (negative), 1 (weak), 2 (moderate) and 3 (intense). The evaluation was expressed as a product of the score of positive rate and staining intensity. Positive staining was defined as a score of $>2$ and negative staining was scored as 0 or 1 .

Western blot analysis. The HCT116 cells were washed twice in ice-cold PBS, pelleted by centrifugation ( $200 \mathrm{x} g$ for $5 \mathrm{~min}$ ) and stored at $-80^{\circ} \mathrm{C}$. The pellet was resuspended in radioimmunoprecipitation assay buffer (Thermo Fisher Scientific, Inc.) with a Halt Protease Inhibitor Single-Use Cocktail (100X; Thermo Fisher Scientific, Inc.) and centrifuged at $4^{\circ} \mathrm{C}$ and $17,400 \times g$ for $20 \mathrm{~min}$. Total protein concentrations were measured by the Bradford method using Bradford reagent (Bio-Rad Laboratories, Inc., Hercules, CA, USA) and a Smart Spec 3000 spectrometer (Bio-Rad Laboratories, Inc.). Total proteins isolated from cell lines were separated by $4-12 \% \mathrm{NuPAGE}^{\circledR}$ Bis-Tris Precast Gel (Thermo Fisher Scientific, Inc.). Tris-Glycine SDS sample buffer (Thermo Fisher Scientific, Inc.) and 3-Mercapto-1,2-propandiol (Wako Pure Chemical Industries, Ltd., Osaka, Japan) were added to the total protein samples and heated at $100^{\circ} \mathrm{C}$ for $3 \mathrm{~min}$. The 4-12\% Tris-Glycine gels (Thermo Fisher Scientific, Inc.) loaded with the $20 \mu \mathrm{g}$ protein samples were electrophoresed in $100 \mathrm{~V}$ for 100 min using Tris-Glycine SDS Running buffer in Invitrogen $^{\text {TIN }}$ XCell SureLock ${ }^{\text {TM }}$ electrophoresis system (Thermo Fisher Scientific, Inc.). Following electrophoresis, the gel was transferred onto the nitrocellulose membrane using an iBlot Gel Transfer Stacks Nitrocellulose, Mini (Thermo Fisher Scientific, Inc.). After transfer, the nitrocellulose membrane was washed with $25 \mathrm{ml}$ TBS for $5 \mathrm{~min}$ at room temperature and blocked in SuperBlock blocking buffer in PBS (Thermo Fisher Scientific, Inc.). The protein blots were incubated with the anti-KIF4A antibody (dilution, 1:300; catalog no. \#ab122227; Abcam) for 
A
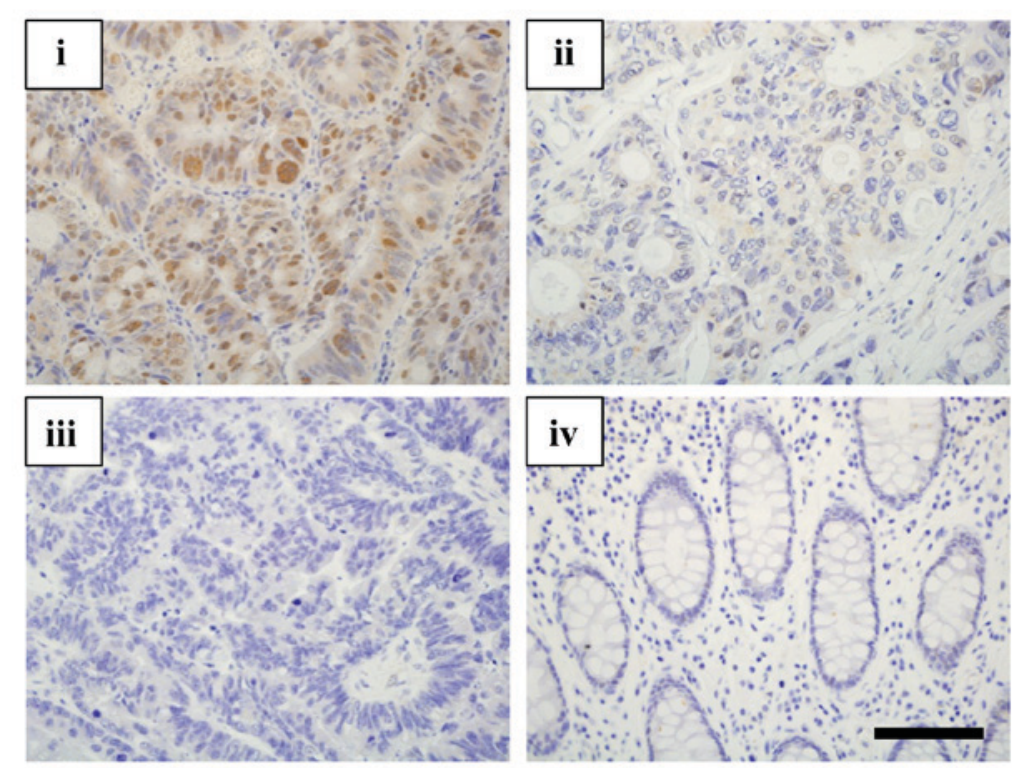

B

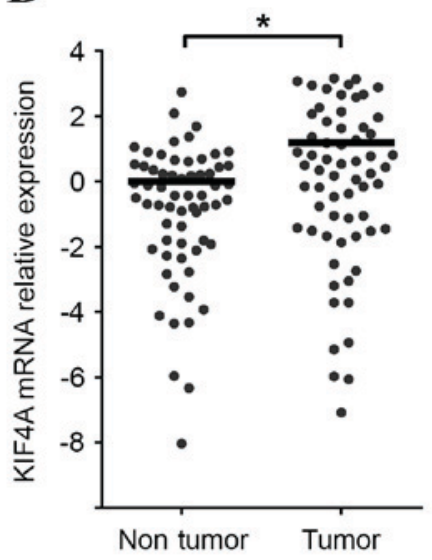

C

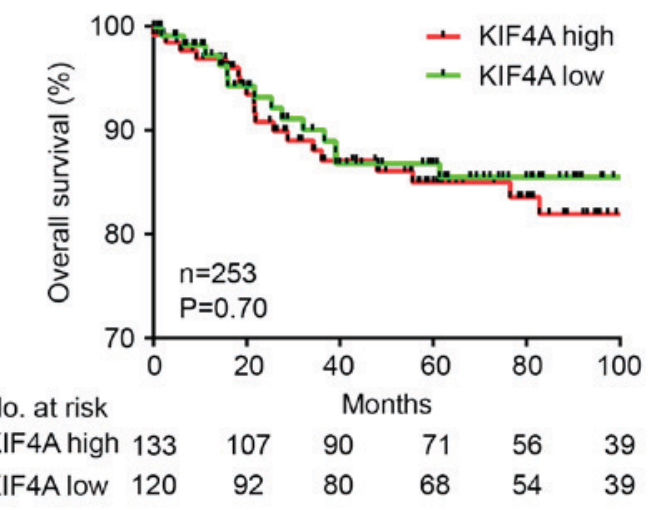

Figure 1. KIF4A expression levels in patients with CRC. (A) Immunohistochemical staining of KIF4A in tissues from patients with CRC. Representative staining intensity: i, intense; ii, weak; iii, negative in tumor tissue; iv, negative in non-tumor tissue. Magnification, x400. (B) Expression levels of KIF4A in tumor and non-tumor tissues from 63 cases. Dot plot represents KIF4A relative expression from reverse transcription-quantitative polymerase chain reaction analysis and expression levels, presented in a $\log 2$ scale, in the tumor tissues were normalized to non-tumor tissues. Horizontal bars indicate mean expression values. "P<0.05 using a Wilcoxon matched pairs test. (C) Kaplan-Meier survival curve of 253 patients with CRC stratified by KIF4A tumor expression levels (high or low). KIF4A, kinesin family member 4A; CRC, colorectal cancer.

$1 \mathrm{~h}$ at room temperature and incubated with goat anti-rabbit immunoglobulin G-horseradish peroxidase (Santa Cruz Biotechnology, Inc., Dallas, TX, USA) as the secondary antibody for $30 \mathrm{~min}$ at room temperature. The protein levels were quantified using a rabbit monoclonal anti- $\beta$-actin antibody (dilution, 1:2,000; catalog no. sc-47778; Santa Cruz Biotechnology, Inc.) as the internal loading control for $1 \mathrm{~h}$ at room temperature. Bound antibodies were detected by enhanced chemiluminescence detection reagents (Thermo Fisher Scientific, Inc.) and visualized by autoradiography (ImageQuant ${ }^{\mathrm{TM}}$ LAS 4000 IR MultiColor imager; Fujifilm Corporation, Tokyo, Japan).

Small interfering RNA (siRNA) transfection. Knockdown experiments were performed using siRNA oligos for KIF4A (\#sc-60888; Santa Cruz Biotechnology, Inc.) and included three target-specific siRNAs and a control siRNA (siRNA-A; \#sc-37,007; Santa Cruz Biotechnology, Inc.) according to the manufacturer's protocol. The day prior to transfection, the HCT116 CRC cell line was seeded at a density of $15 \times 10^{5}$ cells/well in a 6 -well plate. Transfection using Lipofectamine RNAiMAX (Thermo Fisher Scientific, Inc.) with a final concentration of $10 \mathrm{nM}$ siRNA was performed when the cell density was $30-50 \%$ in the 6 -well plates and cells were subsequently incubated at $37^{\circ} \mathrm{C}$ for $48 \mathrm{~h}$.

Cell counting. The cell proliferation rate was assessed using a Cell Counting kit-8 (CCK-8; Dojindo Molecular Technologies, Inc., Kumamoto, Japan) according to the manufacturer's protocol. Briefly, 2x10 $0^{3}$ HCT116 cells and control cells were plated into each well in 96-well plates. The absorbance was measured after $24,48,72,96$ and $120 \mathrm{~h}$ of siRNA transfection. After $1 \mathrm{~h}$ of incubation with $10 \mu \mathrm{l}$ of CCK- 8 reagent at $37^{\circ} \mathrm{C}$, the absorbance was measured at a wavelength of $450 \mathrm{~nm}$ using a Benchmark Plus microplate reader (Bio-Rad Laboratories, Inc.). 
Table I. Clinicopathological characteristics and KIF4A IHC expression.

\begin{tabular}{|c|c|c|c|c|}
\hline \multirow[b]{2}{*}{ Characteristics } & \multirow[b]{2}{*}{ Total $(n=258)$} & \multicolumn{2}{|c|}{ KIF4A IHC } & \multirow[b]{2}{*}{ P-value } \\
\hline & & Positive $(n=132)$ & Negative $(n=126)$ & \\
\hline Age & & & & 0.64 \\
\hline$\geq 65$ & 142 & 75 & 69 & \\
\hline$<65$ & 116 & 57 & 59 & \\
\hline Gender & & & & 0.49 \\
\hline Male & 149 & 79 & 70 & \\
\hline Female & 109 & 53 & 59 & \\
\hline Stage & & & & 0.12 \\
\hline 0 & 10 & 2 & 8 & \\
\hline I & 40 & 23 & 17 & \\
\hline II & 93 & 43 & 50 & \\
\hline III & 75 & 48 & 27 & \\
\hline IV & 40 & 16 & 24 & \\
\hline Tumor location & & & & 0.66 \\
\hline Proximal & 86 & 42 & 44 & \\
\hline Distant & 89 & 49 & 40 & \\
\hline Rectum & 83 & 41 & 42 & \\
\hline Histology $y^{a}$ & & & & 0.24 \\
\hline Tub1 & 120 & 59 & 61 & \\
\hline Tub2 & 106 & 63 & 43 & \\
\hline Por & 10 & 3 & 7 & \\
\hline Muc & 19 & 5 & 14 & \\
\hline Other & 3 & 0 & 3 & \\
\hline Depth & & & & 0.22 \\
\hline Tis & 10 & 2 & 8 & \\
\hline $\mathrm{T} 1$ & 26 & 13 & 13 & \\
\hline $\mathrm{T} 2$ & 32 & 22 & 10 & \\
\hline $\mathrm{T} 3$ & 172 & 95 & 82 & \\
\hline $\mathrm{T} 4$ & 18 & 5 & 13 & \\
\hline Lymphatic invasion & & & & 0.35 \\
\hline Absent & 155 & 71 & 84 & \\
\hline Present & 95 & 59 & 36 & \\
\hline Venous invasion & & & & 0.54 \\
\hline Absent & 59 & 28 & 31 & \\
\hline Present & 199 & 104 & 95 & \\
\hline Lymph node metastasis & & & & $<0.01$ \\
\hline Negative & 155 & 71 & 84 & \\
\hline Positive & 95 & 59 & 36 & \\
\hline Liver metastasis & & & & 0.59 \\
\hline Negative & 226 & 117 & 109 & \\
\hline Positive & 32 & 15 & 17 & \\
\hline
\end{tabular}

P-values were calculated using Fisher's exact test for age, gender, lymphatic invasion, venous invasion, lymph node metastasis and liver

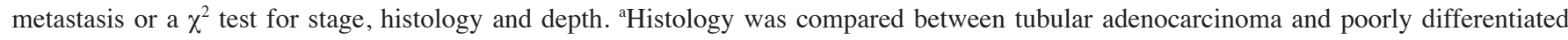
adenocarcinoma. KIF4A, kinesin family member 4A; IHC, immunohistochemistry; tub1, well differentiated; tub2, moderately differentiated; por, poorly differentiated; muc, mucinous adenocarcinoma; Tis, tumor in situ.

Statistical analysis. Mann Whitney test, Fisher's exact test, a $\chi^{2}$ test and Wilcoxon matched pairs test were performed by GraphPad Prism 6.0 (GraphPad Software, Inc. La Jolla, CA, USA). Data of cell viability analysis are shown as the 
A
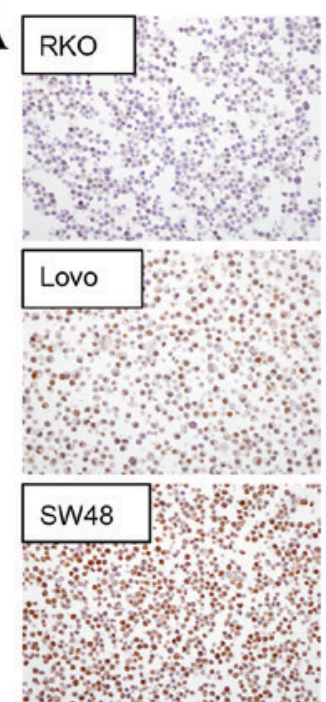

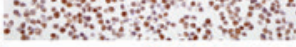
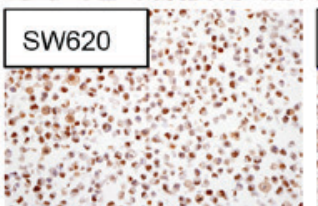

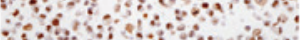
HCT116
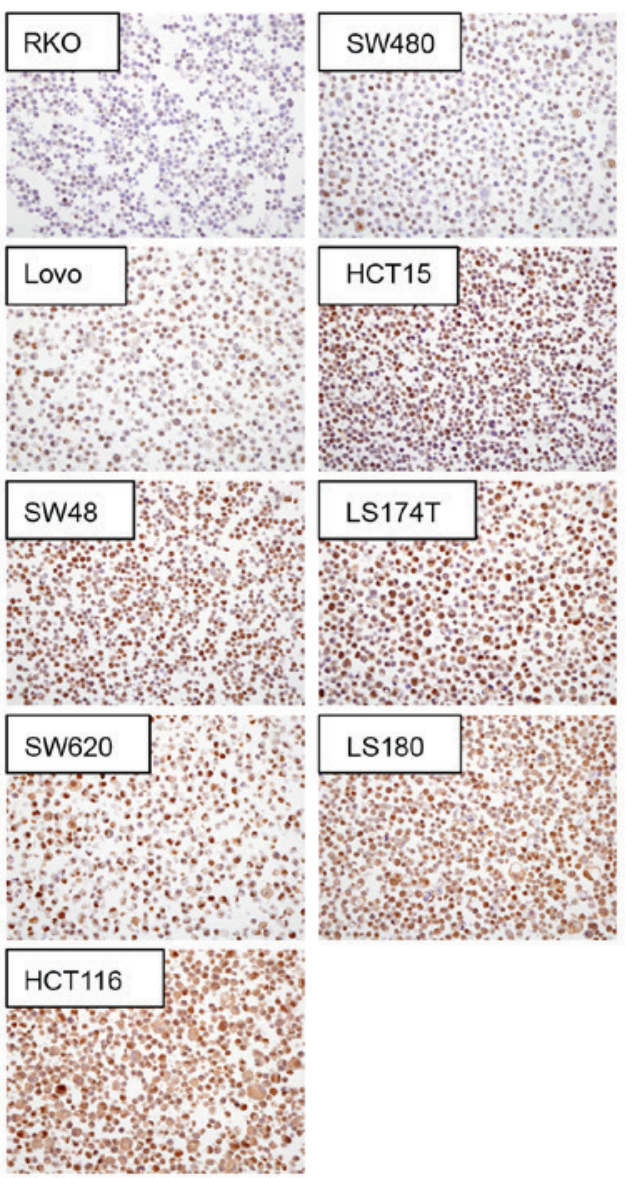

D

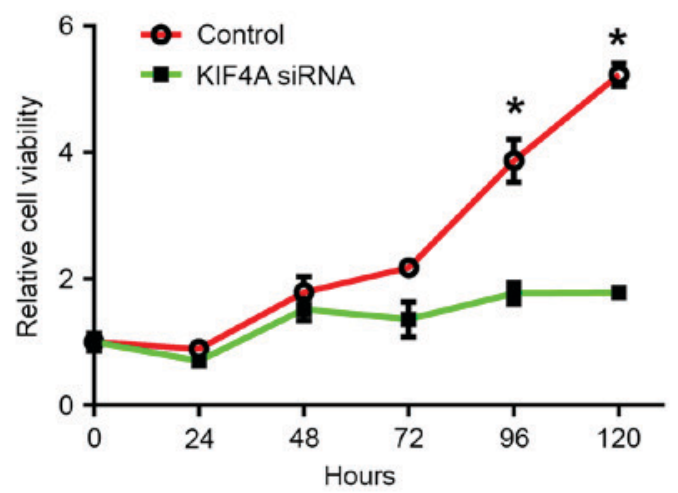

\section{B}

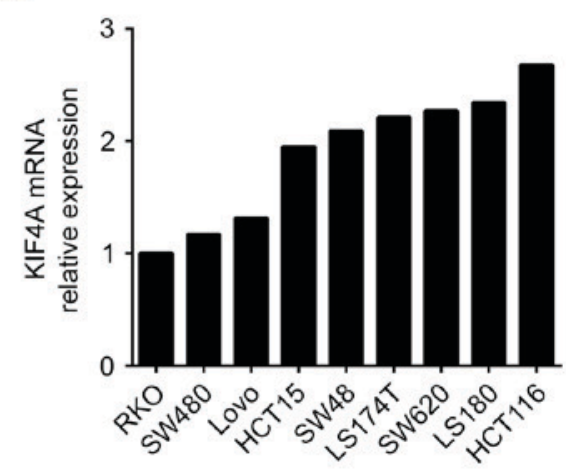

C

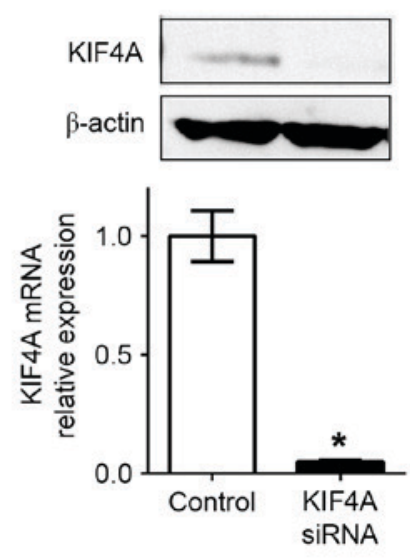

Figure 2. KIF4A expression levels in colon cancer cell lines. (A) Immunohistochemical staining of KIF4A in human colon cancer cell lines. Magnification, $\mathrm{x} 400$. (B) RT-qPCR analysis of KIF4A expression levels in colon cancer cell lines. Relative KIF4A mRNA expression levels to RKO cells $(\mathrm{RKO}=1)$ were analyzed (normalized to $\beta$-actin). (C) Western blot and RT-qPCR analysis of KIF4A knockdown in HCT116 cells (KIF4A-siRNA) and control cells. $\beta$-actin was used as a loading control. KIF4A mRNA expression levels relative to control (control=1) are normalized to $\beta$-actin levels. (D) Cell viability analysis using Cell Counting kit-8 assay in KIF4A knockdown HCT116 and control HCT116 cells. KIF4A knockdown decreases cell viability compared with the control cells. Data are mean \pm standard deviation. ${ }^{*} \mathrm{P}<0.05$. RT-qPCR, reverse transcription-quantitative polymerase chain reaction; KIF4A, kinesin family member 4A; siRNA, small interfering RNA.

mean \pm standard deviation. Survival rate curves were generated using the Kaplan-Meier method and compared by the log-rank test. $\mathrm{P}<0.05$ was considered to indicate a statistically significant difference.

\section{Results}

KIF4A is upregulated in CRC samples. KIF4A expression was evaluated using IHC staining in 258 patients with CRC (Fig. 1A). KIF4A expression was positive in 132 cases
(51.1\% with scores of 2 or 3) and negative in 126 cases (48.9\% with scores of 0 or 1). KIF4A expression levels were observed in the nucleus and cytoplasm of cancer cells, whereas no expression was observed in the normal mucosa. mRNA expression levels of KIF4A were analyzed and compared between tumor and adjacent non-cancerous tissues. KIF4A mRNA expression was elevated in tumor tissues in 63 of the 258 available cases (2.26-fold increase; Wilcoxon matched pairs test, $\mathrm{P}=0.0013$ ) suggesting KIF4A may have an oncogenic role in CRC (Fig. 1B). 
A

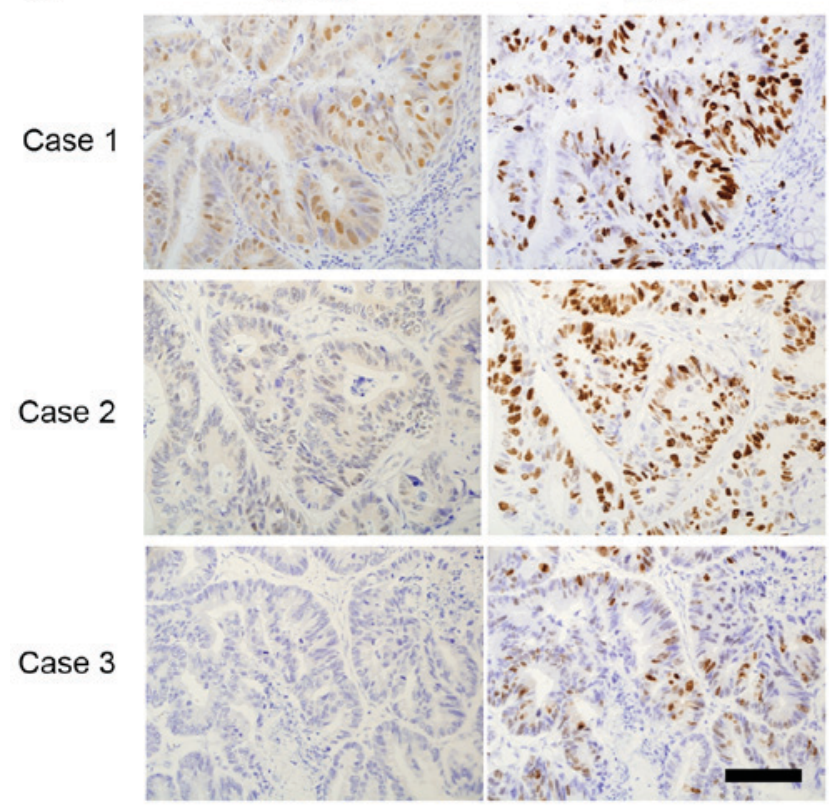

B

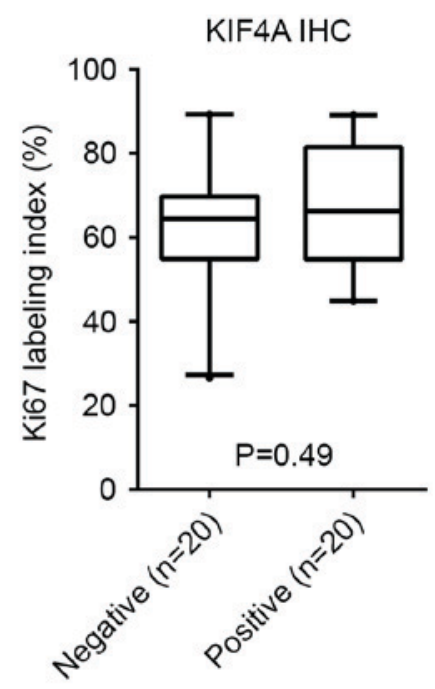

Figure 3. Ki-67 labeling index and KIF4A IHC in tissues from patients with CRC. (A) Representative images of KIF4A and Ki-67 staining in three CRC cases. Of the 40 cases that were stained with Ki-67, half were KIF4A positive patients ( $=20$ ) and half were KIF4A negative patients ( $=20$ ). Magnification, $\mathrm{x} 400$. (B) Box plot comparing the percentage of Ki-67 labeling index between the case with KIF4A positive staining (n=20) and the case with KIF4A negative staining $(\mathrm{n}=20)$. Data are presented as the median, 5 and $95 \%$ percentiles, and upper and lower quartiles. Mann Whitney test. KIF4A, kinesin family member 4A; CRC, colorectal cancer; IHC, immunohistochemistry.

KIF4A expression levels and the clinicopathological characteristics were evaluated in patients with CRC (Table I). The positive expression of KIF4A was significantly associated with positive lymph node metastasis $(\mathrm{P}<0.05)$. However, KIF4A expression levels were not associated with age, gender, tumor location, TNM stage, depth of invasion, venous invasion or liver metastasis. Notably, as KIF4A is located on chromosome Xq13.1, the clinical significance of KIF4A expression in each gender was investigated. However, KIF4Aexpression levels did not associate with any clinicopathological characteristics in male or female patients. Additionally, Kaplan-Meier analysis demonstrated that there was no association between the increase in KIF4A levels and overall survival rate $(\mathrm{P}=0.70$; Fig. 1C).

Knockdown of KIF4A inhibition cell growth in colon cancer cells. To evaluate the role of KIF4A in colon cancer progression, gene knockdown technology was used to investigate cell proliferation. KIF4A expression levels in RKO, SW480, Lovo, HCT15, SW48, LS174T, SW620, LS180 and HCT116 colon cancer cell lines were evaluated to select appropriate cells for further experiments in the current study. KIF4A protein expression levels were examined using IHC staining (Fig. 2A) and KIF4A mRNA expression was evaluated using RT-qPCR (Fig. 2B). Concordant with the IHC results, KIF4A mRNA expression was highest in the HCT116 cells compared with the eight other colon cancer cell lines and therefore was used for further experiments.

The knockdown of KIF4A using siRNA oligonucleotides in the HCT116 cells (KIF4A-siRNA) confirmed that the downregulation of KIF4A affected the mRNA and protein levels (Fig. 2C). Although no morphological changes were observed in the KIF4A-depleted cells, cell proliferation was attenuated. There was a significant decrease after $96 \mathrm{~h}(\mathrm{P}<0.05)$ in the cell growth of the KIF4A-siRNA treated cells compared with the control cells (Fig. 2D).

KIF4A does not associate with positive Ki-67 labeling index results in $C R C$. To further evaluate whether $K I F 4 A$ accelerates cell proliferation in CRC, Ki-67 IHC staining was performed on 40 patient tissue samples (Fig. 3). The association between the KIF4A staining results and the Ki-67 labeling index was also investigated; however, no significant association was observed (Mann Whitney test; $\mathrm{P}=0.49$; Fig. 3).

\section{Discussion}

The present study identified that KIF4A expression levels are increased in tumor samples from patients with CRC and this may be associated with positive lymph node metastasis. The tumor mRNA and protein expression levels of KIF4A were upregulated in patients with CRC. Previous studies have established that KIF4A expression levels are increased in a number of malignant tumors and are associated with poor patient prognosis (12-16). Concordant with these previous studies, the results of the present study indicate a potential oncogenic role for KIF4A in CRC. However, no significant associations between KIF4A protein expression levels and patient survival rate were observed and further investigation is required to identify if KIF4A may be an effective prognostic biomarker for CRC.

In addition, the present study found that the downregulation of KIF4A suppressed the cell proliferation of colon cancer cells, further suggesting that KIF4A is associated with CRC progression and metastasis. Similarly, it was reported that mutated KIF4A in colon cancer cells lengthens the duration of mitosis and 
reduces the speed of cell proliferation compared with wild-type cells (10). The knockdown of KIF4A expression levels has also been demonstrated to suppress cellular proliferation in the SBC-5 lung squamous cell carcinoma cell line (13). The downregulation of KIF4A may induce cell cycle arrest in oral squamous cell carcinoma (15). As KIF4A is involved in regulating the M phase of the cell cycle and controls cellular proliferation via activation of the spindle assembly checkpoint (10), the level of cell cycle arrest identified in cells with KIF4A knockdown was similar to the level observed following the use of microtubule inhibitors (15). A previous study also reported that the downregulation of KIF4A is associated with chemosensitivity in breast cancer cells and demonstrated that KIF4A is directly mediated by doxorubicin-induced cell apoptosis via the upregulation of poly(ADP-ribose) polymerase-1 (21). Therefore, KIF4A expression levels are hypothesized to promote cell malignancy and lymph node metastasis in CRC. However, the association between KIF4A function and the chemosensitivity of CRC cells identified in the current study requires further investigation.

Several studies have reported a tumor suppressor role for KIF4A $(14,22)$. In total 13/23 (56.6\%) gastric carcinoma cases identified reduced expression levels of KIF4 compared with corresponding adjacent normal tissues (14). These 13 cases demonstrated a significant association with poorer differentiation of gastric cancer cells. In addition, in vitro experiments found that KIF4A expression inhibits gastric cancer cell proliferation (14). Another study reported that the loss of KIF4 may trigger tumor formation; embryonic stem cells in the KIF4 knockout mouse model had mitotic defects associated with the loss of a molecular motor function and generation of aneuploidy (22). Notably, the loss of KIF4A expression may result in the onset of carcinogenesis in a number of cell lines from the NCI-60 Human Tumor Cell Line Screen (22). In the present study, the effect of KIF4A expression levels on cell proliferation was investigated in patients with CRC. When comparing KIF4A expression levels and the $\mathrm{Ki}-67$ index, no significant association was observed. Therefore, the functional role of KIF4A remains to be determined and further experimental and mouse model studies (KIF4A transgenic or knockout mice) are required.

In conclusion, to the best of our knowledge the present study is the first to demonstrate an association between the KIF4A expression status and a functional role in CRC. These results suggest that KIF4A may be a potential therapeutic target and this may improve clinical outcomes of patients with CRC.

\section{Acknowledgements}

The present study was supported by JSPS KAKENHI (grant no. $15 \mathrm{k} 10143)$.

\section{References}

1. Siegel RL, Miller KD and Jemal A: Cancer statistics, 2016. CA Cancer J Clin 66: 7-30, 2016.

2. Venook AP, Weiser MR and Tepper JE: Colorectal cancer: All hands on deck. Am Soc Clin Oncol Educ Book: 83-89, 2014.

3. de Gramont A, Figer A, Seymour M, Homerin M, Hmissi A, Cassidy J, Boni C, Cortes-Funes H, Cervantes A, Freyer G, et al: Leucovorin and fluorouracil with or without oxaliplatin as first-line treatment in advanced colorectal cancer. J Clin Oncol 18: 2938-2947, 2000 .
4. Douillard JY, Cunningham D, Roth AD, Navarro M, James RD, Karasek P, Jandik P, Iveson T, Carmichael J, Alakl M, et al: Irinotecan combined with fluorouracil compared with fluorouracil alone as first-line treatment for metastatic colorectal cancer: A multicentre randomised trial. Lancet 355: 1041-1047, 2000.

5. Goldberg RM, Sargent DJ, Morton RF, Fuchs CS, Ramanathan RK, Williamson SK, Findlay BP, Pitot HC and Alberts SR: A randomized controlled trial of fluorouracil plus leucovorin, irinotecan and oxaliplatin combinations in patients with previously untreated metastatic colorectal cancer. J Clin Oncol 22: 23-30, 2004.

6. Tournigand C, André T, Achille E, Lledo G, Flesh M, Mery-Mignard D, Quinaux E, Couteau C, Buyse M, Ganem G, et al: FOLFIRI followed by FOLFOX6 or the reverse sequence in advanced colorectal cancer: A randomized GERCOR study. J Clin Oncol 22: 229-237, 2004.

7. Nakagawa T, Tanaka Y, Matsuoka E, Kondo S, Okada Y, Noda Y, Kanai $Y$ and Hirokawa N: Identification and classification of 16 new kinesin superfamily (KIF) proteins in mouse genome. Proc Natl Acad Sci USA 94: 9654-9659, 1997.

8. Lawrence CJ, Dawe RK, Christie KR, Cleveland DW, Dawson SC, Endow SA, Goldstein LS, Goodson HV, Hirokawa N, Howard J, et al: A standardized kinesin nomenclature. J Cell Biol 167: 19-22, 2004.

9. Miki H, Okada Y and Hirokawa N: Analysis of the kinesin superfamily: Insights into structure and function. Trends Cell Biol 15: 467-476, 2005.

10. Wandke C, Barisic M, Sigl R, Rauch V, Wolf F, Amaro AC, Tan CH, Pereira AJ, Kutay U, Maiato H, et al: Human chromokinesins promote chromosome congression and spindle microtubule dynamics during mitosis. J Cell Biol 198: 847-863, 2012.

11. Mazumdar M, Sundareshan S and Misteli T: Human chromokinesin KIF4A functions in chromosome condensation and segregation. J Cell Biol 166: 613-620, 2004.

12. Narayan G, Bourdon V, Chaganti S, Arias-Pulido H, Nandula SV, Rao PH, Gissmann L, Dürst M, Schneider A, Pothuri B, et al: Gene dosage alterations revealed by cDNA microarray analysis in cervical cancer: Identification of candidate amplified and overexpressed genes. Genes Chromosomes Cancer 46: 373-384, 2007.

13. Taniwaki M, Takano A, Ishikawa N, Yasui W, Inai K, Nishimura H, Tsuchiya E, Kohno N, Nakamura Y and Daigo Y: Activation of KIF4A as a prognostic biomarker and therapeutic target for lung cancer. Clin Cancer Res 13: 6624-6631, 2007.

14. Gao J, Sai N, Wang C, Sheng X, Shao Q, Zhou C, Shi Y, Sun S, Qu X and Zhu C: Overexpression of chromokinesin KIF4 inhibits proliferation of human gastric carcinoma cells both in vitro and in vivo. Tumour Biol 32: 53-61, 2011.

15. Minakawa Y, Kasamatsu A, Koike H, Higo M, Nakashima D, Kouzu Y, Sakamoto Y, Ogawara K, Shiiba M, Tanzawa H and Uzawa K: Kinesin family member 4A: A potential predictor for progression of human oral cancer. PLoS One 8: e85951, 2013.

16. Zou JX, Duan Z, Wang J, Sokolov A, Xu J, Chen CZ, Li JJ and Chen HW: Kinesin family deregulation coordinated by bromodomain protein ANCCA and histone methyltransferase MLL for breast cancer cell growth, survival and tamoxifen resistance. Mol Cancer Res 12: 539-549, 2014.

17. Sobin LH GM and Wittekind CH: International Union Against Cancer (UICC) TNM Classification of Malignant Tumors. Oxford, UK, Wiley-Blackwell, 2009.

18. Sobin LH and Compton CC: TNM seventh edition: What's new, what's changed: Communication from the international union against cancer and the american joint committee on cancer. Cancer 116: 5336-5339, 2010.

19. Okano M, Kumamoto K, Saito M, Onozawa H, Saito K, Abe N, Ohtake T and Takenoshita S: Upregulated annexin A1 promotes cellular invasion in triple-negative breast cancer. Oncol Rep 33: 1064-1070, 2015.

20. Livak KJ and Schmittgen TD: Analysis of relative gene expression data using real-time quantitative PCR and the 2(-Delta Delta C(T)) Method. Methods 25: 402-408, 2001.

21. Wang H, Lu C, Li Q, Xie J, Chen T, Tan Y, Wu C and Jiang J: The role of Kif4A in doxorubicin-induced apoptosis in breast cancer cells. Mol Cells 37: 812-818, 2014.

22. Mazumdar M, Lee JH, Sengupta K, Ried T, Rane S and Misteli T: Tumor formation via loss of a molecular motor protein. Curr Biol 16: 1559-1564, 2006.

This work is licensed under a Creative Commons Attribution-NonCommercial-NoDerivatives 4.0 International (CC BY-NC-ND 4.0) License. 